\title{
Experiências artístico-pedagógicas com estudantes do Ensino Médio da Rede Pública do estado do Maranhão
}

Artistic-pedagogical experiences with high school students from public schools in Maranhão

\author{
Andressa Passos do Nascimento \\ Michelle Nascimento Cabral Fonseca
}

Resumo: O principal objetivo deste artigo é analisar o processo de criação dos estudantes-atores/atrizes que participaram da montagem do espetáculo "O Cavaleiro do Destino", uma produção realizada com estudantes do ensino médio da escola Liceu Maranhense. Entende-se que os processos pedagógicos são também processos artísticos, por isso, utilizamos a análise de documentos (entrevistas, relatórios, plano de aulas), assim como as metodologias utilizadas nas oficinas $e$ as estratégias/técnicas utilizadas para composição da encenação, tendo como base principal os autores Grotowski (1987), Ferracini (2003). Realizamos, assim, com essa linguagem artística, um movimento tático de reinvenção do cotidiano escolar, a partir das oficinas. Por fim, utilizo de oficinas extracurriculares, que acabam por agregar ao ensino do teatro, e por representar um estudo sobre o corpo, abre os caminhos de um redescobrimento maior de si.

Palavras chaves: Teatro na escola; Experiência artística; Composição de espetáculo.

Abstract: The main goal of this academic research is to analyze the composition of student-actors and the assembly of the show "The Knight of Destiny" as an artistic production performed with high school students of the Liceu Maranhense school. It is understood that the pedagogical processes are also artistic processes, so we use the analysis of documents (interviews, reports, lesson plan), as well as the methodologies used in the workshops and the strategies/techniques used for composition of the staging, based on the authors Grotowski (1987) and Ferracini (2003). With this artistic language, we made a tactical movement of reinvention of the ordinary school, based on the workshops. At last, this new format adds a lot to the process of teaching theater, as well as a study on how the body opens new way for rediscovery ourselves.

Key words: Theater in the school; Artistic experience; Show composition.

\section{Introdução}

A instituição escolar, principalmente no que diz respeito à sua administração, sofre influências dos mais diversos aspectos: econômicos, políticos, pedagógicos e sociais. Este trabalho ${ }^{1}$, porém, tem como objetivo principal verificar se houve um aproveitamento eficiente no processo de formação dos estudantes que participaram das oficinas do grupo de teatro da

\footnotetext{
1 Financiamento Fundação de Amparo à Pesquisa e ao Desenvolvimento Científico e Tecnológico do Maranhão - FAPEMA
} 
escola Liceu Maranhense ${ }^{2}$ no que tange à expansão de potencialidades vocais e corporais, bem como no desenvolvimento da concentração e consciência do trabalho de grupo, durante as várias camadas que envolveram a montagem do espetáculo "O Cavaleiro do Destino". Além disso, será analisada também a sensibilização artística, principalmente no contexto não-formal de ensino, assim como a superação de estigmas e apropriação de aspectos da identidade cultural maranhense.

\section{Teatro no espaço escolar: onde tudo começou...}

No ano de 2016, o subprojeto do PIBID do curso de Licenciatura em Teatro da Universidade Federal do Maranhão, foi intitulado de "Teatro na Escola: da tradição à contemporaneidade", integrado à duas escolas públicas da capital maranhense, o colégio Liceu Maranhense e o Colégio Universitário-COLUN³ ${ }^{3}$ Uma das principais ações desse subprojeto do PIBID Teatro era o fortalecimento, por meio do desenvolvimento de oficinas de teatro, a formação de habilidades e competências artísticas e pedagógicas dos bolsistas (estudantes de graduação), no contexto de ensino formal e nãoformal. Nesse sentido, as oficinas se encaixavam mais nas características da educação não-formal. Para compreender a diferença entre os dois conceitos:

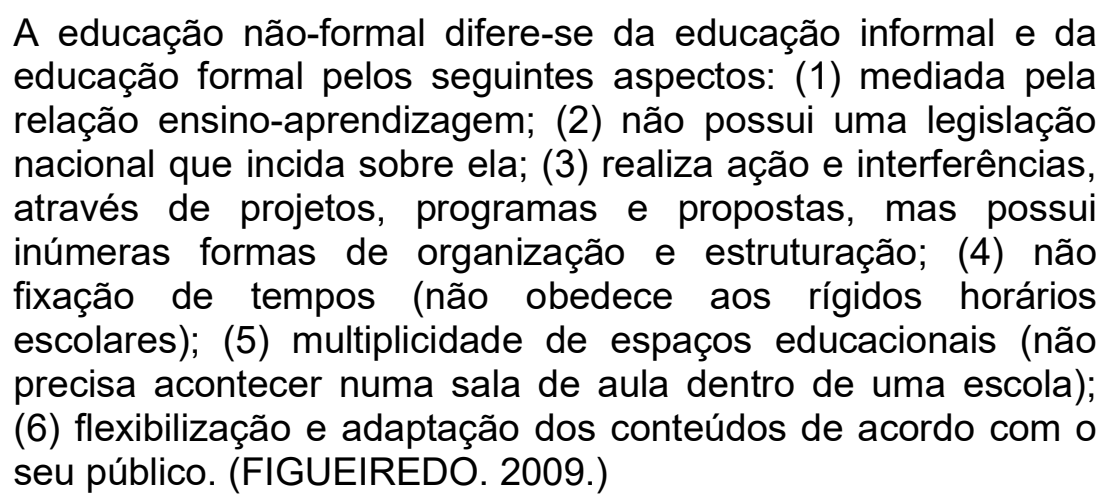

Atentamos, porém, que a proposta de teatro na educação não-formal é que ela seja também um espaço de prática de vivência social, com a criação de

\footnotetext{
2 O Liceu Maranhense é uma tradicional instituição de ensino médio brasileira fundada em 24 de julho de 1838 e localizada em São Luís-MA.

3 Integravam a equipe do Pibid, Coordenação de Área prof. Me. Flávia Andresa Oliveira de Menezes, supervisão no Liceu Maranhense, prof. Me. Gislane Gomes Braga. Bolsistas: Nicolle Machado, João Victor da Silva Pereira, Renato Guterres, Marcelo Morais.
} 
laços de afetividade entre os participantes, valorizando o desenvolvimento e apreciação da linguagem artística, o que justifica a presença de um profissional apto para exercer essa função nesses espaços educativos. Para tal, visando à execução dessas oficinas, criamos um grupo de teatro dentro da escola Liceu Maranhense com estudantes do $1^{\circ}$ ao $3^{\circ}$ ano do ensino médio.

É necessário que o teatro na educação não-formal reacenda a cultura dos indivíduos nela envolvidos, incluindo os (as) professores (as) e estudantes, de modo que a experiência cultural de cada um seja respeitada e esteja presente em todo o trabalho, com o intuito de, não somente dar valor a realidade de cada um, mas indo além, dando a possibilidade dessas experiências perpassarem por todas as atividades.

A convivência em grupo facilita essa interação e promove sua eficácia. Do contrário, cairíamos em um modelo escolar muito criticado na área das artes cênicas, o da Escola Tradicional. A educação não-formal permite que seus praticantes (professores e estudantes) trabalhem e experimentem modelos de experiência que normalmente não são vivenciados na escola formal, como por exemplo, foco na experiência prática, desenvolvimento das potencialidades artísticas, estudo mais aproximado do processo de criação artística, quebra na verticalidade da relação educador-educando, extensão da experiência formativa para fora da escola.

Deve-se pensar sempre em uma formação docente que perpasse por etapas de pesquisa, por transposição didática, aplicação e reflexão dos resultados, com a intenção de atingir um resultado satisfatório com os estudantes. Visto que o teatro na escola é fundamental para emancipação do estudante enquanto indivíduo e ser social, o projeto teve como principal eixo formativo a prática teatral, no que tange o desenvolvimento de percepções extracotidianas e de uma conscientização do uso do seu corpo, proporcionando uma experiência estética teatral dentro da escola. Paranaguá nos diz:

[...] a importância da experiência estética enquanto instância formativa que leva ao saber fazer e ao domínio da prática docente, esses são elementos imprescindíveis [...] implementação de propostas culturais inerentes a produção artística junto à educação não-formal (SANTANA, 2013. p.85). 
Fazer com que os estudantes tivessem de fato uma experiência estéticaartística foi um grande desafio para os pibidianos ${ }^{4}$, tendo em vista que tínhamos um curto tempo (4 meses) para desenvolver as oficinas com o grupo de teatro e também criar um espetáculo para participação do Festival Estudantil- FEMATE5 5 . O que definitivamente nos ajudou a enfrentar este desafio foi o trabalho coletivo dos pibidianos, além do auxílio das duas coordenadoras, prof. Flávia e prof. Gislane, que nos proporcionaram encontros com a intenção de planejarmos e estruturarmos detalhadamente todas as ações realizadas.

E assim, o projeto de oficinas na escola Liceu Maranhense foi sendo desenvolvido, tendo como propósito final a montagem do espetáculo " $\mathrm{O}$ Cavaleiro do Destino"6, obra escolhida por ter sido escrita por um dramaturgo maranhense, um dos requisitos para a participação no Festival.

\section{Adentrando o espaço: reflexões e desenvolvimento das oficinas}

A ideia de espaço é muito relativa, e vai se adequando de acordo com o contexto em que o termo será aplicado. No teatro, ele representa um elemento de grande importância, pois a expressividade é desenvolvida a partir da inserção do corpo no espaço e essa ocupação engloba toda a relação de identidade do sujeito com o mundo, tornando-se um meio de criação através do encontro, da troca e das descobertas.

Ryngaert (2009) diz que o espaço é fundador do jogo teatral. Aqui, a escola será retratada como um local no qual o teatro foi implementado, buscando-se perceber como essa linguagem artística, vivida em modelo nãoformal dentro de um ambiente formal, consegue trabalhar com metodologias que deem abertura para os estudantes se expressarem, sem precisar se encaixar em uma espécie de padrão (de comportamento e aprendizado) que a

\footnotetext{
${ }^{4}$ Termo relacionando aos graduandos de licenciatura em Teatro-UFMA, bolsistas do PIBID. São eles: Marcelo Augusto Morais, Nicolle da Silva Machado, Renato Guterres e João Victor da Silva Pereira.

${ }^{5}$ Festival Maranhense de Teatro Estudantil. Realizado pela Secretaria de Estado da Cultura e Turismo - SECTUR, através do Centro de Artes Cênicas do Maranhão-CACEM.

6 Dramaturgia escrita pelo Prof. Dr. Tácito Borralho da UFMA e Josias Sobrinho músico maranhense no ano de 1976.
} 
própria instituição acaba por estabelecer. Segundo Rodrigues (1986, p.47), o corpo "(...) é o mais natural, o mais concreto, o primeiro e o mais normal patrimônio que o homem possui".

Foi com o intuito de pensar em metodologias que ajudassem esses estudantes a terem outras experiências nesse espaço disciplinar que estabelecemos um olhar especial ao corpo. Sabe-se que existe uma cultura enraizada nas instituições escolares de que corpo, em sua totalidade, é deixado do lado de fora, assim como a cidade e a vida, para valorizar o intelecto e a força de trabalho, como por exemplo: estudantes são enfileirados em carteiras, precisam sentar-se eretos, tudo isso feito para que não haja nenhum tipo de interferência no andamento dos padrões que as escolas acabam estabelecendo.

Por isso, se torna notório que corpo é separado daquilo que ele produz, procedimento que podemos considerar alienante e puramente de interesses econômicos, como Foucault nos aponta, ao propor uma genealogia das instituições carcerárias. O autor disserta acerca da importância dos corpos nesse espaço:

os sistemas punitivos devem ser recolocados em uma certa, 'economia política' do corpo [...], é sempre do corpo que se trata - do corpo e de suas forças, da utilidade e da docilidade delas, de sua repartição e de sua submissão (FOUCAULT, 1997, p. 29).

No caso específico da instituição escolar, a força de trabalho em questão é um vir a ser. Os adolescentes submetidos a este sistema não produzem como os operários de uma fábrica. Sendo assim, a função da escola enquanto instituição disciplinadora é habituá-los às disciplinas que lhes serão impostas posteriormente para, aí, então, terem sua força de trabalho convertida em produção: docilizar os corpos para torná-los produtivos.

Uma maneira de visualizar a questão da docilização dos corpos é observar as diferenças entre escolas que atendem alunos de baixa e alta renda. Quanto mais pobre for o público de uma instituição escolar, mais esta instituição irá se assemelhar a uma fábrica, ou mesmo uma prisão: grandes salas com um grande número de alunos dificultando o olhar individualizado, 
uniformes que buscam domar o corpo e anular as diferenças, controle sobre o cumprimento dos horários, deslocamentos e atividades. Pereira e Bonfim (2006) acreditam que,

em geral, as questões do corpo têm sido vividas e explicitadas como 'corpo-máquina', ou seja, como instrumento funcional e operacional, e não como um ser no mundo, como experiência vivida, como lugar de encontro. (PEREIRA E BONFIM, 2006, p.50)

Por isso, é preciso pensar criticamente acerca da educação que não entende que o adolescente é o que é, mas sim o que ele vai se tornar, negando a sua realidade e o momento presente.

O jovem está na escola para se tornar médico, engenheiro, advogado, ou outra profissão. Mas o que aquele adolescente é? Ao negar o que o estudante traz e vive no presente, negamos também as possíveis experiências reais e significativas, pois se trabalha somente na perspectiva do vir a ser, da virtualidade. Por esses motivos, se fez necessário investigar aspectos metodológicos para um trabalho com o corpo desses estudantes, para que de alguma forma pudéssemos aguçar descobertas e desenvolver suas habilidades corpóreas, para, então, chegarmos na cena com corpos dispostos.

Pavis (2008) destaca que o corpo em cena se configura de duas maneiras:

a. O corpo não passa de um relé e de um suporte da criação teatral, que se situa em outro lugar: no texto ou na ficção representada. O corpo fica, então, totalmente avassalado a um sentido psicológico, intelectual ou moral; ele se apaga diante da verdade dramática, representando apenas o papel de mediador na cerimônia teatral. A gestualidade desse corpo é tipicamente ilustrativa e apenas reitera a palavra.

b. Ou, então, o corpo é um material autorreferente: só remete a si mesmo, não é a expressão de uma ideia ou de uma psicologia. Substitui-se o dualismo da ideia e da expressão pelo monismo da produção corporal: ' $O$ ator não deve usar seu organismo para ilustrar um movimento da alma; deve realizar o movimento com seu organismo' (Grotowski, 1971: p. 91). Os gestos são - ou ao menos se dão como - criadores e originais. Os exercícios do ator consistem em produzir emoções a partir do domínio e do manejo do corpo (PAVIS, 2008, p. 75). 
Pavis traz noções muito interessantes para a cena, a respeito do corpo. Segundo ele, o corpo pode ser um transmissor de mensagens, de ideias, e ao mesmo tempo transmitir estados e emoções. Quanto mais conhecimento temos a respeito do próprio corpo, da própria personalidade, mais podemos nos "entregar" a um personagem. Tudo isso proporciona possibilidades de descobertas de formas como podemos andar, reagir às emoções, as formas de se relacionar com o outro etc. O corpo nos diz quem somos, quais as nossas habilidades motoras e cognitivas, o que nós temos para melhorar, quais são os nossos bloqueios, nossos medos e nossos desejos.

O interessante a se destacar nesse momento é que a vontade de trabalhar como eixo principal o corpo do ator, tem origem nas referências artísticas de todos os pibidianos e na maioria das experiências relatadas a seguir. O caminho pedagógico também foi traçado a partir da vivência artística dos mesmos, que se relaciona muito com o pensamento de Josette Féral (2009): "O teatro que se faz e o teatro que se ensina devem estar ligados". Além do desejo de trazer algo fora da caixinha ${ }^{7}$, diferente do que os estudantes pensam acerca do que é o teatro. Sendo assim, procuramos ter como livro de cabeceira "A arte de não interpretar como poesia corpórea do ator", de Renato Ferracini $(2003)^{8}$, e o "Em busca de um teatro pobre", de Grotowiski (1992) ${ }^{9}$, além de outros do gênero.

Assim, o processo artístico-pedagógico com o Grupo de Teatro do Lice $^{10}$ foi desenvolvido nas seguintes etapas.

Na primeira etapa, ao adentramos o primeiro dia de oficina, era notório e meio assustador que a maioria dos integrantes do grupo, quando questionados sobre suas vontades, no que diz respeito ao próprio desejo de estar no grupo de teatro, não conseguiam se expressar, ou tinha vergonha de falar em público.

\footnotetext{
7 Quando me refiro a palavra "caixinha" quero dizer que na escola, infelizmente, o que a maioria dos estudantes sabem do teatro é com base em novelas e filmes, pensando somente em decorar textos.

${ }^{8} \mathrm{O}$ objetivo principal desta publicação é mostrar a proposta do processo de formação de um ator não interpretativo, tomando por base as experiências técnicas e metodológicas do Lume Núcleo Interdisciplinar de Pesquisas Teatrais da Unicamp.

9 "Teatro pobre", essencial e ritualístico, baseado única e exclusivamente na ação e na transiluminação do ator.

10 O grupo foi montado a partir de livre demanda da escola, inicialmente os pibidianos fizeram divulgação nas salas no turno matutino e noturno e os interessados deveriam comparecer no primeiro dia de encontro.
} 
Lembro como se fosse hoje da primeira oficina que tivemos, a sala estava lotada e eu só ficava perguntando para mim mesmo 'o que é que eu estou fazendo aqui?'. Mas no final acabou sendo muito divertido, fizemos uma dinâmica para aprendermos o nome de cada um e nos questionaram o motivo de querermos fazer teatro (MARTINS, 2018, informação verbal).

Então, nos primeiros encontros começamos a realizar jogos teatrais e dramáticos baseados nas propostas metodológicas de Boal (1997), Koudela (2011), Beatriz Cabral (2006), entre outros. Foram inseridas propostas de entrosamento que contemplavam a improvisação teatral e noções de espaço postuladas pelos referidos autores. Depois desses primeiros encontros, os estudantes mostraram-se um pouco mais entrosados e dispostos a externar sugestões e sensações.

A partir dessas ocasiões iniciais, começamos a trabalhar aspectos como concentração, percepção espacial, auditiva e sensorial por meio de jogos e improvisações teatrais, exercícios de expressão corporal e técnica vocal. Estas eram atividades mais técnicas, que tinham como objetivo desenvolver uma série de habilidades, e também geravam grande impacto num ponto crucial de interesse do grupo: a concentração e noções de espaço.

$\mathrm{Na}$ segunda etapa, uma vez que estavam mais à vontade com as atividades e pessoas, os estudantes receberam aprofundamento de alguns conteúdos de corpo e voz para o ator. Fomos colocando como prioridade um trabalho com corpo, já que o grupo começou a nos apresentar uma melhora significativa na articulação e intensidade da voz, conseguindo, assim, conciliar com a prática corporal.

Começamos a pensar em jogos que traziam dinâmicas corporais entre os envolvidos: estudantes e professores. Para que pudéssemos proporcionar um contato com o seu próprio corpo, utilizando a imaginação e as emoções, onde eles e elas pudessem estabelecer uma espécie de enfrentamento com o espaço do entorno.

Esse espaço foi sendo preenchido e construído à medida que os estudantes se relacionaram consigo mesmo e com o outro no ambiente, de forma participativa e criativa. Nossa referência pedagógica era o corpo do ator, 
fonte de invenção criadora, a partir do qual se reflete no espaço. Segundo Soares (2010, p. 128),

[...] é através da relação de descoberta e ocupação do espaço que o jogo teatral confere ao aluno um lugar de identidade no processo criativo. É também pela exploração do corpo no espaço que aluno constrói o conhecimento do fazer teatral, organizando, a partir daí uma noção de teatralidade.

Estimulando a noção de corporeidade com os participantes das oficinas, já começamos a perceber o entendimento deles do corpo em teatro, que o corpo no teatro não é trabalhado como algo isolado da consciência, mas a partir da vivência do momento, da sua presença expressiva, que materializa pensamentos, reflexões, sensações e sentimentos. Que se deseja comunicar, agindo como mediador entre consciência e mundo.

Cada atividade tinha o seu propósito e o mais importante, eu acho, era poder se conectar com o seu amigo, ter cuidado e respeito com ele, além de trabalhar o nosso próprio corpo fisicamente e conhecê-lo melhor. (MARTINS, 2018, informação verbal).

Na terceira etapa, a partir do estímulo da consciência corporal dado ao grupo, cada um começou a se conhecer, a saber que os seus corpos tinham potencialidades. Começamos, então, a incentivar uma busca por maneiras particulares para sua expressão artística. Revisitamos os estudos de Grotowski (1987), que buscam por meios práticos e objetivos atingir modos de presença potentes no corpo do ator em cena. Ele salienta:

Não se pode ensinar métodos pré-fabricados. Não se deve tentar descobrir como representar um papel particular, como emitir a voz, como falar ou andar. Isto tudo são clichês, e não se deve perder tempo com eles. Não procurem métodos préfabricados para cada ocasião, porque isso só conduzirá a estereótipos. Aprendam por vocês mesmos suas limitações pessoais, seus obstáculos e a maneira de superá-los. (GROTOWSKI, 1987, p. 186).

Portanto, nessa etapa passamos por um percurso que contou com as ideias e pensamentos citados acima, sempre refletindo acerca da busca pessoal de cada ator/atriz. 
Dessa maneira, conseguiríamos desenvolver uma organicidade nos integrantes do grupo, o que acaba sendo mais interessante do que seguir "métodos pré-fabricados", como diz Grotowski, tentando alicerçar uma prática pessoal de interpretação. Isto não significa, porém, negar os métodos (se é que existem, na sua total originalidade), mas significa estar livre para perceber as suas singularidades e ter uma prática pessoal de treinamento ou representação/interpretação.

$\mathrm{Na}$ quarta etapa, a partir dessas experiências com o corpo e suas singularidades, demos continuidade à montagem do espetáculo, buscando jogos que estimulassem comportamentos a partir das propostas dos personagens da dramaturgia. Como já mencionado, o texto trabalhado foi "O Cavaleiro do Destino ${ }^{11 "}$, que conta com muitos personagens místicos e lendas maranhenses. Borralho nos aproxima melhor da estrutura desse texto quando diz:

\begin{abstract}
Esqueleto da ação: procura/ perseguição do destino. A linguagem literária/ dramática seria a poesia em ritmo de cordel, a mais adequada para aliar diálogos entre personagens humanos e personagens fantásticos. A estrutura ritmada das falas facilitaria o entendimento dos ouvintes e o cântico dos atores. O texto foi escrito em episódios, em vez de atos ou cenas, e os personagens surgem a cada cena, desempenhando seus papeis, cumprindo suas missões e não retomando mais à trama. (BORRALHO, 2005, p. 88).
\end{abstract}

Borralho (2005), diz que no texto ocorrem "diálogos entre personagens humanos e personagens fantásticos", esses personagens fantásticos são (na indicação original do texto) bonecos, mas nessa encenação não pretendíamos trabalhar com teatro de bonecos, e sim com atrizes e atores humanos. A partir deste ponto, começamos a dar um direcionamento à construção (corpóreovocal) desses personagens fantásticos.

Não buscamos situar essas figuras místicas/fantásticas em um local, tempo ou motivação, mas descobrir como elas agiam: andavam, deitavam, falavam, gritavam. Por isso, não houve uma análise do texto como enredo para preparação de oficinas, mas uma extração de cada personagem para propor

\footnotetext{
11 Dramaturgia que nos leva a uma viagem ao imaginário fantástico através de poesia/ música da cultura popular maranhense.
} 
uma movimentação a partir do imaginário e deformações de cada um, acionando o material sensitivo, crítico e pessoal.

Observamos que os estudantes trazem consigo umas deformações, representação grotesca das corporeidades; o grotesco provoca estranhamento, além de desprezar os territórios devidamente separados por uma ordem lógica e natural das coisas.

o corpo grotesco não está separado do mundo, não está isolado, acabado nem perfeito, mas ultrapassa-se a si mesmo, franqueia seus próprios limites. Coloca-se ênfase nas partes do corpo em que ele se abre ao mundo exterior, isto é, onde o mundo penetra nele ou dele sai ou ele mesmo sai para o mundo, através de orifícios, protuberâncias, ramificações e excrescências, tais como a boca aberta, os órgãos genitais, seios, falo, barriga e nariz. (BAKHTIN, p. 23, 1987).

Para Almeida (2007), essa imagem grotesca do corpo segundo Bakhtin obedece a um alto índice de hiperbolização, não apenas porque é difamando, como ressaltaram alguns estudiosos anteriores ao russo, mas por ser, segundo ele, ambivalente.

Para trabalhar a questão da construção desse imaginário, os arquétipos e os mitos são os elementos primordiais para compreensão. Durand (1985) recupera a ideia de arquétipo de Jung como imagem essencial e avança apresentando o já citado percurso antropológico no qual o arquétipo se insere, ou seja, na base de toda produção humana.

Arquétipo como uma das primeiras imagens que vêm à mente do ser humano em seu desenvolvimento inicial, ou ainda como matriz primordial que é preenchida cultural e historicamente por imagens e símbolos; arquétipos enquanto núcleos organizadores das produções culturais dos sujeitos. Essas imagens do grotesco e de deformações nos auxiliaram na composição dos personagens.

Tivemos como aliado o conceito de pré-expressividade, que tem como essência tudo aquilo que vem antes da expressão do personagem. É onde o ator produz, onde ele pode trabalhar todos os elementos técnicos e orgânicos de suas ações físicas e vocais. É o nível da presença onde o ator ou atriz 
trabalha, independente de quaisquer elementos externos, quer seja texto, personagem ou cena. Segundo Ferracini,

A pré-expressão, portanto, é o alicerce do trabalho nãointerpretativo, pois é nesse nível que o ator busca aprender e treinar uma maneira operativa, técnica e orgânica de articular, tanto suas ações físicas e vocais no espaço como, e principalmente, sua dilatação corpórea, sua presença cênica e a manipulação de suas energias. (2003, p. 88).

Para trabalharmos essa pré-expressividade, o primeiro passo das oficinas era o aquecimento: antes de iniciarmos qualquer espécie de trabalho com os estudantes/atores/atrizes, sempre avisávamos que o ator deve aquecer seu corpo, e que isso é uma prática eficiente para despertar e preparar o corpo, comprovada e executada por teóricos e cias de teatro. Nosso aquecimento não era somente de musculatura, mas também se propunha a acionar energias ${ }^{12}$ que fizessem esses adolescentes entrar no trabalho.

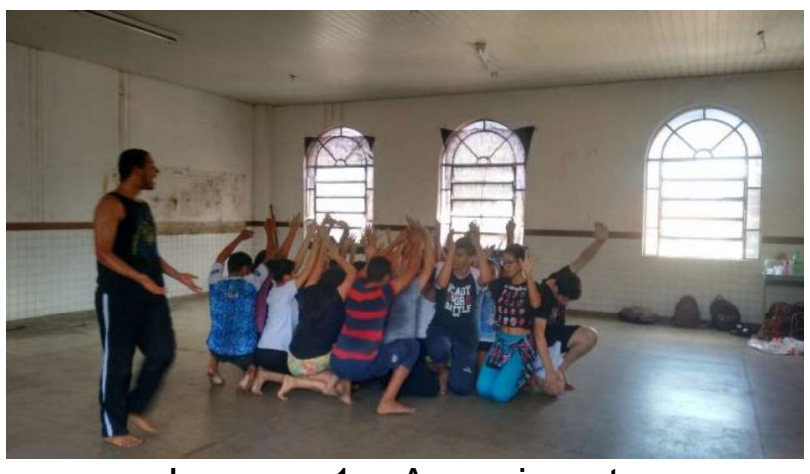

Imagem 1 - Aquecimento

Fonte: acervo pessoal

O caminho escolhido para reativar essas energias guardadas foi a técnica de exaustão.

Trata-se de um treinamento físico intenso e ininterrupto, e extremamente dinâmico, que visa trabalhar com energias potenciais do ator. 'Quando 0 ator atinge 0 estado de esgotamento, ele conseguiu, por assim dizer, 'limpar' seu corpo

\footnotetext{
${ }^{12}$ Entendo energia a partir das noções propostas pela antropologia teatral. Barba caracteriza a energia do ator: "para o ator a energia apresenta-se na forma de um como, não na forma de um como, não na forma de um quê. Como movimentar-se. Como ficar imóvel. Como mise-enscene, ou seja, mise-en-vision a sua presença física e transformá-la em presença cênica, e, portanto, expressão. [...] Contudo, para o ator é muito útil pensar neste como na forma de um quê, de uma substância impalpável que pode ser manobrada, modelada, cultivada, projetada no espaço, absorvida e levada a dançar no interior do corpo. Não são fantasias. São imaginações eficazes" (Barba, 1994, p. 77).
} 
de uma série de energias 'parasitas', e se vê no ponto de encontrar um novo fluxo energético mais 'fresco' e mais 'orgânico' que o precedente' (BURNIER, 1994, p. 33).

Nossa proposta era sempre instigar os estudantes a realizarem movimentos grandes, aleatórios, ocupando todo o espaço da sala, sendo realizado de maneira dinâmica e envolvendo todo o corpo. A única coisa que evitávamos nesse processo era ter que interrompê-lo por alguma adversidade dos envolvidos. Quando percebíamos que estavam cansados, diminuíamos a intensidade, o ritmo e a fluidez, ou mudávamos a dinâmica das ações, mas nunca parávamos.

Acreditamos que essa quebra brusca, essa possível interrupção, por um suposto cansaço, seria um "fio" condutor para se esvair todo o trabalho de energização adquirido naquele momento. Por isso sempre tínhamos uma atenção dobrada na condução desses exercícios, que faziam eles e elas irem para um outro estado corpóreo.

Contudo, em muitas ocasiões a entrega dos estudantes em relação ao treinamento foi satisfatória. Este é um processo gradativo, pois trabalhar com adolescentes não é uma tarefa fácil; o estranhamento em relação aos exercícios foi grande, além da dificuldade para soltar o corpo por completo em um primeiro momento e se relacionar com o outro.

Um dia, em especial, vocês pediram para que nós fechássemos os nossos olhos e deitássemos no chão e em seguida sentir o corpo uns dos outros sem usar as mãos, foi no mínimo muito intenso. Eu tinha muita dificuldade no começo porque eu não aceitava muito bem meu corpo e sentia um certo nojo dos outros corpos. As oficinas me ajudaram MUITO como pessoa, evolui demais depois dessas experiências. Aprendi a olhar o próximo com mais empatia e aceitar mais os corpos. Como vocês diziam, 'isso é só uma carcaça, o que importa é o que está dentro' (VELOSO, 2018, informação verbal).

A imagem demonstra esse relato da estudante, 


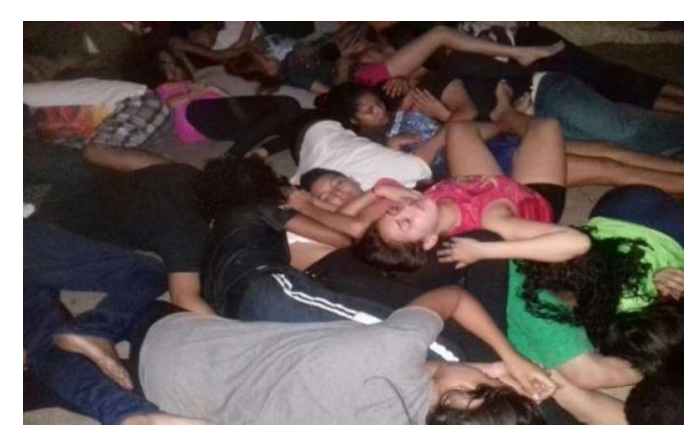

Imagem 2 - Corpos dos estudantes interlaçados

Fonte: acervo pessoal

A timidez e a interação com o corpo do outro se mostrou um dos maiores obstáculos que enfrentamos. Pensando em como poderíamos superálos, a estratégia escolhida pelos pibidianos foi a do exercício de interação, onde formávamos uma dupla com os estudantes que apresentavam maiores dificuldades. Essa estratégia deu força para que eles não ficassem deslocados nos treinos, pois sempre estavam inseridos, e assim fomos insistindo nos treinamentos energéticos. Os estudantes foram se conhecendo e interagindo melhor e, nesse momento, começamos a perceber o quanto foi necessária a nossa participação. Eles acabavam vendo os pibidianos como um espelho, uma inspiração, e isso corroborou para que a energia não se perdesse, incentivando o entendimento de que corpo é só mais uma coisa que nos compõe.

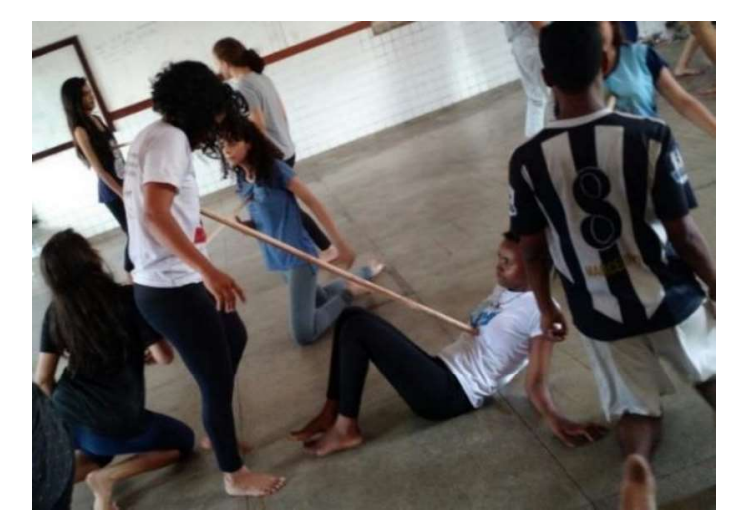

Imagem 3 - Interação dos pibidianos com os estudantes

Fonte: acervo pessoal

Foram muitas adversidades, mas não desistimos, e foram essas interferências que nos possibilitaram nossa reinvenção e procura por uma melhora no ato de ministrar as oficinas. Paramos para refletir se o caminho que estávamos trilhando seria possível, pois o que apresentávamos aos estudantes 
eram técnicas para atores profissionais. Apesar disso, a nossa determinação e nossa crença no potencial do grupo nos fez continuar no caminho, abraçando o corpo, o presente, a presença e a vida, ou nas palavras de Carminda: "Sugerimos que a atitude da invenção seja usada como ferramenta para a produção do conhecimento da arte do teatro nas condições de crise em que se encontra no contexto escolar" (ANDRÉ, 2007, p. 23). Estávamos proporcionando além de uma experiência, um conhecimento no teatro que foi sendo adquirido no decorrer das oficinas.

O próximo passo seria o momento que os/as estudantes/atores/atrizes já estariam com os seus corpos dispostos a alcançar outras possibilidades, como a organicidade e as suas energias potenciais. O estudante começou a entender o seu corpo, que ele também é um meio de comunicação, compreendendo suas limitações e a dos companheiros, começando a ter consciência corpórea.

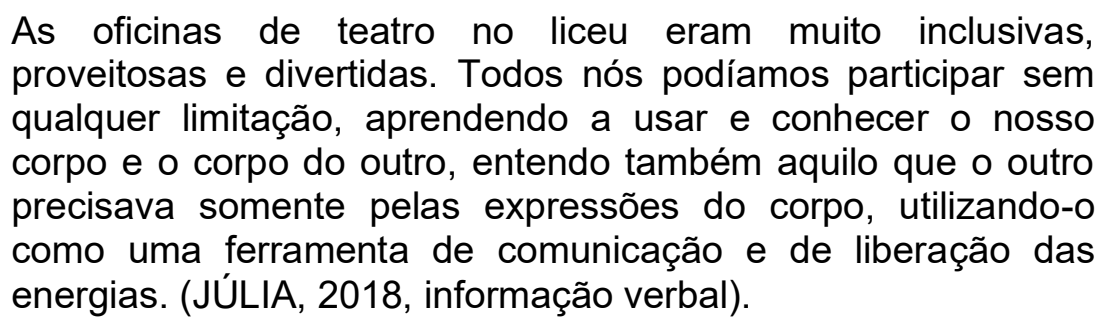

Começávamos a instigá-los a memorizar o que acontecia nos treinos, para que eles/elas conseguissem posteriormente se colocar no espaço e no tempo de maneira extracotidiana, diferente do comum. Hoje nós podemos considerar essa etapa como momento de um treinamento técnico que, para Ferracini,

É uma nova aprendizagem, na qual o ator deve reeducar seu
corpo para que ele se transforme em um corpo cênico,
potencialmente artístico, a fim comunicar ao público, de
maneira organizada e otimizada, toda sua organicidade e sua
vida. O treinamento técnico modela o corpo e faz com que o
ator aprenda a desenhar e manipular as diferentes
intensidades de energia e tensão muscular. (FERRACINI,
2003, p.30).

Não tínhamos dado uma técnica fechada de representação para os/as estudantes/atores/atrizes; nosso objetivo não foi, em momento algum, que 
aprendessem uma técnica, mas que tivessem que treinar e aprender no seu corpo os elementos que permeiam o extracotidiano

Em um certo dia de oficina, fomos ao auditório, afastamos todas as cadeiras, deixando livre o espaço, apagamos as luzes e começamos a colocar músicas de vários ritmos. Os alunos começaram a sentir a música e a dançar. O ritmo ia aumentando e eles exploravam todos os planos possíveis; em seguida, começou uma interação entre o grupo, com momentos em que cantavam as músicas, outros gritavam. Tudo era muito instintivo. Desde então, percebemos que tínhamos conseguido trazer uma espécie de "liberdade", onde todos os tabus que os atores e atrizes sentiam tinham acabado, estavam livres, então, para fazer tudo o que queriam e sentiam necessidade de fazer naquele espaço.

O dia em que tivemos liberdade de expressar o corpo através das músicas colocadas pelos pibidianos no auditório, com as luzes apagadas. Nesse dia cada pessoa poderia dançar e liberar as energias da forma que quisesse e ao máximo que pudesse (JÚLIA, 2018, informação verbal).

Alguns elementos caminharam conosco nesse processo de redescobrimento. Foram eles: dilatação corpórea, desequilíbrio ou equilíbrio precário, oposição, base, olhos e olhar, equivalências e variação de fisicidade. Elementos estes utilizados pela cia Lume Teatro $^{13}$, que se inspira nas teorias do Eugenio Barba.

Usando esses princípios do Lume e Grotowski, conseguimos acionar e descobrir nos estudantes/atores/atrizes a organicidade corpórea de cada um, como cada um se comporta com esse extracotidiano, que foi um dos nossos principais aliados para montagem do espetáculo.

A partir desse momento, os treinamentos técnicos de exaustão, nessa etapa do trabalho, eram bem-vindos. Um desses treinamentos, o "Jogo dos Bichos", que fora realizado nas etapas iniciais e também nas etapas finais das oficinas, era acompanhado por uma música e o jogo consistia em que eles carregassem os bichos por várias partes do corpo, onde nós alterávamos os

13 Fundado em 1985, LUME Teatro se tornou uma referência mundial na pesquisa da arte do ator. O grupo já se apresentou em mais de 28 países, tendo atravessado quatro continentes, desenvolvendo parcerias especiais com mestres da cena artística mundial. 
níveis de velocidades. Na primeira experiência, não tivemos um resultado muito agradável, mas em uma segunda vez eles se divertiram muito, mesmo com a chegada do cansaço. Podemos observar na fala da atriz,

E depois, de tanto ficar com passarinho na cabeça, carregando um elefante e tendo um grilo que não parava em lugar nenhum, várias imagens que fizemos com nossos corpos, veio aquele momento de relaxar o corpo e a mente. Será inesquecivel aquela, massagem e aquele ultimo momento. A roda que fizemos, e na qual depois começamos a cantar, sendo assim o encerramento de mais um dia do nosso encontro, um sucesso, com varios aprendizados. Porque a cada aula, a cada momento, ou ação, as lembranças do que fizemos ficarão guardados em nossos pensamentos. Informação escrita ${ }^{14}$

Ao perceber a energia que pairava nos treinos, tomávamos consciência de como o corpo pode se encaminhar para um outro lugar, totalmente desconhecido. Com isso, passamos a ter corpos com novas maneiras de se comportar em vida. Através dos relatos dos atores e atrizes, registra-se grande mudança da desenvoltura dos mesmos no ambiente escolar e familiar, além de relatarem maior facilidade de relacionamento e concentração.

Nesse meio de "caos" e descobertas, começaram a surgir possibilidades, onde o ator/atriz poderia levar para cena algo que fosse orgânico.

Todas as nossas aulas terminavam com uma roda de debate e leitura do protocolo que era feito por algum dos estudantes sobre a aula anterior. Esse momento se mostrava muito importante pois estimulava a escrita, a fala e a reflexão, o que tornava os estudantes vigilantes acerca dos conteúdos teóricos das atividades práticas, graças à oportunidade de fala. Eles passaram, além disso, a ter maior cuidado no registro e na fidelidade à norma culta gramatical. A exposição pública dessas reflexões passa a convidá-los a pesquisas particulares sobre os temas trabalhados. Essa prática comunga com alguns estudiosos da pedagogia do teatro, como podemos observar abaixo,

\footnotetext{
14 Trecho retirado de um protocolo de aula feito durante o processo de oficinas, por Tatiane de Freitas, no dia 25/09/2016, atriz do espetáculo.
} 
O valor educacional presente nessas práticas ressalte-se, precisa ser compreendido a partir do relevante caráter pedagógico intrínseco à própria experiência teatral. Assim, o teatro quando adentra a instituição educacional, não precisa, e não deve ser um teatro "escolarizado", "didatizado", para que tenha importância educacional; ao contrário, deve ser preservado em sua potencialidade, pois seu principal vigor pedagógico está no caráter artístico que lhe é inerente. (DESGRANGES, 2006, p.91)

$\mathrm{Na}$ quinta etapa, passando do momento de descobertas corpóreas, começamos a apresentar o texto para os estudantes, mas apresentamos por meio de estímulos à improvisação em cima do imaginário do que seria a movimentação de cada figura, seu temperamento e vícios (tiques de linguagem e nervosos).

A partir de uma divisão da dramaturgia em 7 (sete) episódios (Couro Velho, Princesa Magalona, A Manguda, Cavalo do Cão, A velha que vira porco, A serpente guardiã e A barca de D. João) trabalhamos improvisos, com algumas orientações para a busca do exagero em cada movimento e oralidade, não seguindo necessariamente uma ordem entre essas cenas. Dividimos grupos e solicitamos propostas para fragmentos isolados, sem esclarecer os pontos de ligação entre cada um. Isso proporcionou a eles um estímulo a autonomia de criação, como podemos observar no trecho abaixo,

Das oficinas a principal lembrança que eu tenho é que vocês deixaram muito na nossa mão pra gente construir o personagem, vocês deram ideias iniciais e separaram e cada equipe iria montar o corpo com base nos personagem do texto, o meu corpo de montagem, até aonde eu me lembro não foi do cavaleiro a princípio, se não me engano foi do coro velho que foi um grupo bem maior assim que a gente conseguiu entender e mencionar que o coro velho ia ser um pedaço de coro que assustava uma cidade, a gente ficou naquela como a gente vai passar isso pro corpo? Porque um coro a gente tem a ideia que seria similar a um tecido uma coisa larga e leve e tentar colocar isso no corpo foi muito difícil a princípio eu lembro que dentro do grupo a gente discutiu se ia colocar isso como uma movimentação batendo o braço se seria um corpo mais rígido e a gente tentou inicialmente eu lembro todo mundo se abraçando junto até que surgiu a imagem que a gente foi melhorando que foi a do corpo solto e assim foi bem marcante então essa oficina ficou marcada porque eu lembro que a gente foi vendo como os outros também puderam montar. (LINDOSO, 2018, Informação verbal). 
Apresentadas as propostas, registramos potências de deformação e possibilidade de cena em cada um, notando que mesmo sem o texto, os estudantes já conseguiam criar corporalmente.

Com as propostas de possibilidades de cenas para o espetáculo sem ter utilizado a dramaturgia em mãos, guardamos um tempo para ler a dramaturgia, analisar, criar e recriar cenas teatrais considerando seus aspectos estéticos, históricos, sociais e culturais.

Foi, então, com a leitura da dramaturgia que surgiu uma das grandes dificuldades do processo: ao longo do debate sobre o texto, ouve-se uma voz "eu odiei esse texto". Em seguida, foram aparecendo outras vozes. Naquele momento, parecia que o trabalho feito por nós estava indo por água abaixo. Os estudantes não conseguiam imaginar o texto com as imagens corporais, por isso, resolvemos ouvir de todos suas opiniões pessoais sobre o texto e o que recebemos foram respostas vagas, ou que dialogavam com um lugar comum do que eles estão habituados a ver em teatro, cinema, televisão e internet, no caso de terem essas referências.

Obtivemos também respostas que diziam respeito ao que eles imaginavam causar boa impressão numa plateia de pais e amigos - uma certa busca por aprovação. Não podíamos e nem tínhamos como fazer a alteração do texto. Observamos essa insatisfação na fala do ator Gustavo Lindoso,

Eu, particularmente, odiei o texto, eu tentei ler, tentei ver e eu não me via no texto, acho que porque quando a gente começou, quando eu comecei a participar do PIBID, em 2015, a gente estava trabalhando com um texto muito tradicional, onde a gente tinha delimitado 'ah é um aluno de uma escola, fazer um aluno de uma escola é fácil por que eu sou um aluno de uma escola'. Então eu estava praticamente fazendo aquilo que eu faço diariamente, mas quando chegou um texto onde tinham criaturas místicas, onde tinha espadas e armas, onde tinham seres que nunca eu tinha ouvido falar, coisas que fazem parte da nossa cultura, mas que foram se perdendo ao longo do tempo, e talvez até por isso tenha feito o baque inicial, porque a gente não conhece a nossa cultura. Nós, maranhenses, não conhecemos a nossa cultura, tanto é que a gente só começa a ver história do MA do terceiro ano do ensino médio para fazer prova da UEMA porque eles exigem, porque se não exigissem a gente não ia estudar a história do MA. Querendo ou não, isso está ligado com a relação cultural 
que a gente tem com nosso meio." (LINDOSO, 2018, Informação verbal).

De acordo com os parâmetros curriculares nacionais (PCN), o "Tema Transversal Pluralidade Cultural", deve ser oferecido aos estudantes como uma oportunidade de conhecimento sobre a sua cultura local. Além disso, a Lei de Diretrizes e Bases da Educação Nacional (LDB 9394/96), em seu Art. $1^{\circ}$, destaca que a educação deve abranger os processos formativos que se desenvolvem nas manifestações culturais. Infelizmente, mesmo com todos esses aparatos, as escolas negligenciam as próprias leis que foram criadas em prol de uma melhoria da educação, acarretando uma falta de proximidade do estudante à sua cultura e história.

Graças a essa falta de empatia e identificação com o texto, por conta da sua linguagem popular, tivemos que pensar em estratégias pedagógicas de como aproximaríamos esses estudantes/ator/atriz à dramaturgia. O momento era delicado, muitos de nós, pibidianos, tivemos inicialmente uma rejeição ao texto também, então foi de extrema necessidade que nós nos aproximássemos mais da dramaturgia e que a conhecêssemos de ponta a ponta, para, assim, tentarmos uma reaproximação com os atores e atrizes.

Vale aqui ressaltar, mais uma vez, que nós, bolsistas-pibidianos, estávamos inseridos diretamente em todo o processo, participando de todas as atividades, pois, no trabalho com o ensino do teatro sabemos a extrema importância do papel de quem conduz. Essa nossa participação nos deu forças para continuar acreditando que conseguiríamos realizar a montagem final.

Nunca tivemos para com os estudantes uma postura hierárquica, agindo como os detentores do saber. Sempre nos posicionamos como observadores, participantes e propositores, mantendo uma relação de diálogo aberto com o grupo. Segundo Koudela (1999, p. 115),

É tarefa do coordenador desvendar crises e desmascarar soluções esquemáticas, costumeiras, convencionais. A confiança que os participantes depositam no coordenador advém da sua capacidade de decifrar aquilo que não é solução, contribuindo com perguntas, dúvidas, multiplicidade de pontos de vista comparações, lembranças, experiências. 
Como coordenadores, nos reunimos para juntos pensarmos o que poderíamos fazer. A primeira providência foi solicitar a cada estudante uma pesquisa sobre os personagens e lendas que estavam na peça, pois eles não conseguiam visualizar o espetáculo, devido ao contexto do texto não estar próximo à realidade deles. Essa pesquisa teve como intuito abrir as fronteiras do conhecimento e da aprendizagem, de modo a propiciar uma relação de diálogo.

Outro ponto que nós, pibidianos, acionamos foi nossas vivências artísticas no quesito de atuação, de modo a experimentar a peça. Começamos em nós mesmos um processo de pensar as cenas do espetáculo e, quando já estava tudo mais fechado, nós experimentávamos juntos.

Por que pensar a cena sem a presença do grupo de estudantes? Como dito anteriormente, registramos potências de deformação e possibilidade de cena em cada um dos participantes, e foi a presença desse material em mãos que nos possibilitou uma possível construção de objetivos para as cenas. $O$ intuito de desenhar essas cenas antes de levar para a sala de ensaio foi para exclusivamente mostrar ao grupo que era possível realizar a montagem do espetáculo. Por isso também não chegamos com uma proposta de entendimento do texto, mas uma tentativa de sedução a partir da magia e possibilidades dos personagens.

O primeiro passo foi apresentar comissões de personagens para que cada estudante escolhesse uma ou mais. Então passamos a trabalhar jogos de contato e batalha entre essas comissões, mapeando partituras corporais e vocais que mais alimentavam a interação entre eles. Foram feitas muitas atividades de resistência física e contato, onde utilizamos esses exercícios para que os estudantes se acostumassem com as cenas em conjunto, com proximidade física constante e que se acostumassem com a dinâmica de movimentação, quase sempre intensa.

Frequentemente inseríamos objetivos em cada improvisação, assim as cenas iam se delineando e afunilando um padrão de comportamento em cada comissão. Não impúnhamos uma marcação a ser seguida exatamente, mas um objetivo a ser alcançado em cada cena. Além disso, sempre que surgia a 
oportunidade, reforçávamos que "não existe erro", que tudo pode ser incorporado ao processo, se assim o quisermos, e o que define a permanência de um elemento não é sua utilidade ou notoriedade, mas as próprias leis do processo.

Nessa etapa, não havia mais vazios expressivos na sala. Todos pediam a palavra e contribuíam, tanto no processo de construção das cenas, quanto nos debates ao término de cada aula, trazendo materiais frutos de pesquisa própria e sem obrigatoriedade.

Conseguimos aproximá-los do universo da peça e, como última etapa do processo de criação, distribuímos o texto conforme a escolha de cada aluno e contemplando a participação de todos. As falas e textos musicados foram encaixados dentro das movimentações já estabelecidas e dos jogos recorrentes entre esses personagens. Então, buscamos conforme o caráter fantástico do texto, uma não-lógica comportamental dos atores-atrizes, dando lugar a uma admissão do estranho como afirmação de lugar no mundo, acionando assim a comicidade, estranhamento e crítica.

As cenas criadas emanciparam-se da visualidade dramatúrgica, acionando sentidos que não intencionavam corroborar o texto, mas que tinham a ver com características e expressões das posições dos atores/atrizes; poéticas bizarras para uma cena grotesca. Sendo assim, a principal matéria de encenação que possuíamos era o corpo dos participantes. Como visto, desde o começo das oficinas eles foram estimulados a ocupar, desenhar com suas possibilidades corpóreas o espaço.

\section{Conclusão}

O presente trabalho foi desenvolvido acreditando-se que um grupo de teatro estudantil pode se consolidar como um espaço de criação artística dentro da escola. Um espaço onde o estudante, na troca com o outro e através da experiência do outro, possa encontrar suporte para ressignificar a lacuna existente nas suas relações escolares e familiares. Que a partir do processo de criação, o sujeito busque um redescobrimento de si, ou de um novo encontro com seu eu, e que lentamente vá escrevendo uma nova história, dando 
possibilidade de produzir uma outra forma de subjetivação, que lhe permita uma nova relação com os seus desejos.

Pretendeu-se, além desta experiência, mostrar que realmente existem outras possibilidades de promoção da ação teatral no espaço escolar, mediante a oficina extracurricular.

Verificou-se o aproveitamento realizado a partir do acontecimento teatral que emergiu no grupo de teatro, pois a maioria dos integrantes do mesmo no ano, em 2016, começou a frequentar espaços culturais da cidade, além de muitos que continuaram no grupo de teatro no ano de 2017 entraram no elenco de outra peça, chamada "Cabra Marcado para Morrer".

Em 2017, eu estava à procura de uma atriz para participar de um monólogo, chamei uma das atrizes (Leilane) do "O Cavaleiro do Destino" para apresentar "A mulher que dita". A mesma aceitou e mais uma vez "se jogou" no espetáculo. Outra atriz do espetáculo, Raquel, se encontra no estado de Minas Gerais cursando Teatro na UFSJ - Universidade Federal de São João del Rei.

Vejamos o quão frutífero foi o espaço de descoberta criado junto a esses estudantes; um lugar para se conhecer melhor e adquirir novas percepções. Hoje, frequentemente, os encontramos em espaços culturais da cidade, mostrando que a relação que criamos não foi a de ex-alunos/exprofessores, mas, sim, de novos amigos da arte.

A montagem do espetáculo "O Cavaleio do Destino" nos deu a oportunidade de ver a escola como um espaço tão potente de criação teatral quanto os espaços especializados nisso, assumindo que precisamos nos despir de preconceitos, como do talento ou da aptidão às artes; todos têm desejos e isso é suficiente para incendiar um palco. É preciso combater as mortes em vida, encher nossos estudantes de apetite, fazê-los crer que suas opiniões importam e movimentam a existência em sociedade. Para finalizar, tenho dito: precisamos ver a escola como um espaço potente para criação artística!

\section{Referências}


ANDRÉ, Carminda Mendes. O teatro pós-dramático na escola. 2007. 206 f. Tese (Doutorado em educação) - Faculdade de Educação, Universidade de São Paulo, São Paulo. 2007.

ALMEIDA, Rogério Caetano de. 0 corpo grotesco como elemento de construção poética nas obras de Augusto dos Anjos, Mário de Sá Carneiro e Ramón López Velarde. 2007. Dissertação (Mestrado em Estudos Comparados de Literaturas de Língua Portuguesa) - Faculdade de Filosofia, Letras e Ciências Humanas, Universidade de São Paulo, São Paulo, 2007. Disponível em: https://teses.usp.br/teses/disponiveis/8/8156/tde-02102007 Acesso em: 31/07/2021.

BAKHTIN, Michail. A cultura popular na Idade Média e Renascimento: o contexto de Rabelais. São Paulo: UCITEC, 1987.

BOAL, Augusto. 200 exercícios e jogos para o ator e o não-ator com vontade de dizer algo através do teatro. $13^{a}$ ed. Rio de Janeiro: Civilização Brasileira, 1997.

BORRALHO, Tácito. 0 boneco - do imaginário popular maranhense ao teatro: uma análise de O cavaleiro do destino. São Luís: SESC, 2005.

BRASIL. "LEI n. ${ }^{\circ}$ 9394, de 20.12.96, estabelece as diretrizes e bases da educação nacional", in Diário da União, ano CXXXIV, n. 248, 23.12.96.

BURNIER, Luis Otávio. A arte do ator: da técnica à representação. Elaboração, codificação e sistematização de ações físicas e vocais para o ator. 1994. 340 f. Diss. Tese (Doutorado em Comunicação e Semiótica) -Pontifícia Universidade Católica, São Paulo, 1994.

CABRAL, Beatriz. Drama como método de ensino. São Paulo, Hucitec, 2006.

DESGRANGES, Flávio. Pedagogia do Teatro: provocação e dialogismo. São Paulo: Hucitec, 2006.

DURAND, G. Sobre a exploração do imaginário, seu vocabulário, métodos e aplicações transdisciplinares: mito, análise e mitocrítica. Revista da Faculdade de Educação, v. 11, n. 1-2, p. 244-256, 1985.

FÉRAL, Josette. Teatro Performativo e pedagogia. Entrevista. Sala Preta, v.1, n. 09, pp.255-268, dez. 2009. Disponível em: <http://revistasalapreta.com.br/index.php/ salapreta/article/view/300/299>.

Acesso em: 25/07/2021.

FERRACINI, Renato. A Arte de Interpretar como Poesia Corpórea do Ator. Campinas-São Paulo, Ed. Unicamp, Imprensa Oficial do Estado S.A., 2003.

FIGUEIREDO, Ricardo. O ensino do teatro na educação não-formal: contribuições para a formação inicial do professor de teatro. In: REUNIÃO CIENTÍFICA DE PESQUISA E PÓS-GRADUAÇÃO EM ARTES CÊNICAS, 5. Anais... São $\quad$ Paulo, 2009. Disponível em 
https://www.publionline.iar.unicamp.br/index.php/abrace/article/view/2642:

Acesso em:27/ 07/ 2021.

FOUCAULT, Michel. Vigiar e Punir. Petrópolis: Vozes, 1997.

GROTOWSKI, Jerzy. Em busca de um teatro pobre. Tradução por Aldomar Conrado. Rio de Janeiro: Civilização Brasileira, 1987.

KOUDELA, Ingrid Dormien. Jogos Teatrais. São Paulo: Perspectiva, 2011. , Ingrid Dormien.Texto e Jogo: uma didática brechtiniana. São Paulo: Perspectiva; Fapesp, 1999.

PAVIS, Patrice. Dicionário de Teatro. Tradução de J. Guinsburg e Maria Lúcia Pereira. São Paulo: Perspectiva, 2008.

PEREIRA, Lucia Helena Pena; BONFIM, Patrícia Vieira. A corporeidade e o sensível na formação e atuação docente do pedagogo. Revista Contexto \& Educação, v. 21, n. 75, p. 45-68, 2006.

RODRIGUES, J. C. Tabu do Corpo. $4^{\text {a }}$ ed. Rio de Janeiro, Dois Pontos, 1986.

RYNGAERT, Jean-Pierre. Jogar, Representar. São Paulo: Cosac Nayf, 2009.

SANTANA, Arão Paranaguá de. Experiência e conhecimento em teatro. São Luís: EDUFMA, 2013.

SOARES, Carmela. Pedagogia Teatral, uma poética do efêmero: o ensino do teatro na escola pública. São Paulo: Hucitec, 2010.

\section{Entrevistas}

JÚLIA, ANA. Entrevista concedida para a monografia intitulada "OS SETE ENCONTROS: análise da composição do espetáculo teatral $O$ cavaleiro do Destino", São Luís- MA, 27 set. 2018.

LINDOSO, GUSTAVO. Entrevista concedida para a monografia intitulada "OS SETE ENCONTROS: análise da composição do espetáculo teatral $O$ cavaleiro do Destino", São Luís- MA, 15 out. 2018.

MARTINS, EDIGAR GONÇALVES. Entrevista concedida para a monografia intitulada "OS SETE ENCONTROS: análise da composição do espetáculo teatral O cavaleiro do Destino", São Luís- MA, 16 out. 2018.

VELOSO, ELLEN. Entrevista concedida para a monografia intitulada "OS SETE ENCONTROS: análise da composição do espetáculo teatral O cavaleiro do Destino", São Luís- MA, 20 set. 2018.

\section{Sobre os autores:}

Andressa Passos do Nascimento 
andressa.passos@discente.ufma.br

Artista- docente, atriz, produtora cultural e pesquisadora. Mestranda em Artes Cênicas (UFMA), graduada em Teatro Licenciatura (UFMA). Docente da Educação Básica do município de Magé- RJ. Contato:

\section{Michelle Nascimento Cabral Fonseca}

michelle.ncf@ufma.br

Artista- docente, atriz, palhaça e pesquisadora. Pós-Doutorado em Artes Cênicas pela Universidad de Zaragoza-UNIZAR na Espanha. Doutorado em comunicação (PUC/RS), Mestrado em História comparada (UFRJ), bacharel em Artes Cênicas- Direção teatral (UNIRIO). Docente do curso de Licenciatura em Teatro do Departamento de Artes Cênicas (UFMA) e Coordenadora do Mestrado em Artes Cênicas - PPGAC/UFMA.

Recebido em: 31/07/2021

Aprovado em: 24/09/2021 